\title{
Application of a 5-item brief symptom rating scale to evaluate suicide risk in elderly inpatients
}

\author{
Dongping Zhu', Zhu Zhu' ${ }^{2}$, Jiayi Gu ${ }^{3}$, Wei $\operatorname{Luan}^{4}$ \\ ${ }^{1}$ Department of Intensive Care Unit, Renji Hospital, School of Medicine, Shanghai Jiaotong University, Shanghai, China; ${ }^{2}$ Department of VIP \\ Clinic Department, Renji Hospital, School of Medicine, Shanghai Jiaotong University, Shanghai, China; ${ }^{3}$ Shanghai University of Medicine \& Health \\ Sciences, Shanghai, China; ${ }^{4}$ Department of VIP Medical Office, Renji Hospital, School of Medicine, Shanghai Jiaotong University, Shanghai, China \\ Contributions: (I) Conception and design: D Zhu; (II) Administrative support: W Luan; (III) Provision of study materials or patients: Z Zhu; (IV) \\ Collection and assembly of data: J Gu; (V) Data analysis and interpretation: Z Zhu; (VI) Manuscript writing: All authors; (VII) Final approval of \\ manuscript: All authors. \\ Correspondence to: Wei Luan. Department of VIP Medical Office, Renji Hospital, School of Medicine, Shanghai Jiaotong University, 160 Pujian Road, \\ Shanghai 200127, China. Email: luanwei_renji@163.com.
}

Background Suicide rates among hospital inpatients increase with age. Choosing a simple and appropriate suicide risk assessment tool can assist medical staff to identify high-risk individuals in time, and reduce the inpatient suicide rates.

Methods: A total of 1,841 elderly inpatients in the Renji Hospital South Campus, Shanghai Jiaotong University of Medicine from April to August 2020 were randomly selected as the participants for a crosssectional study. Their conditions were assessed by BSRS-5, Barthel index (BI), and numeric rating scale (NRS). Then, the software SPSS 23.0 (IBM Corp., Armonk, NY, USA) was applied to create a database and statistically analyze the results.

Results: According to the BSRS-5 score, 1,825 participants (99.1\%) had no suicide risk (0-3 points) and 16 participants $(0.9 \%)$ had suicide risk (4-24 points). Subsequently, univariate analysis was performed with the BSRS-5 score as the dependent variable and participant gender, age, self-care ability, and pain intensity as independent variables. The results showed that self-care ability $(\mathrm{F}=3.195, \mathrm{P}=0.000)$ and pain intensity $(\mathrm{F}=3.247, \mathrm{P}=0.001)$ were the main risk factors for suicide. Finally, to investigate the relationship of suicide risk with self-care ability and pain intensity, the scores of the 3 scales (BSRS-5, BI, NRS) were assigned, and then the data were analyzed by logistic regression. The results showed that self-care ability assignment was statistically significant $(\mathrm{P}=0.009<0.05, \mathrm{~B}=-0.657)$, suggesting that self-care ability score affected the suicide risk in elderly inpatients. Specifically, the weaker their self-care ability, the higher the suicide risk.

Conclusions: Suicide prevention strategies should take self-care ability into account, which is a crucial influencing factor of suicide risk in elderly inpatients. The BSRS-5 assessment tool is recommended to assess suicide risk in elderly inpatients, which can then contribute to the establishment of a 3-level safety system for suicide prevention in elderly inpatients.

Keywords: The elderly; inpatients; suicide risk assessment; self-care ability

Submitted Apr 20, 2021. Accepted for publication Jun 29, 2021.

doi: 10.21037/apm-21-1443

View this article at: https://dx.doi.org/10.21037/apm-21-1443

\section{Introduction}

It has been reported that 1 suicide happens every 40 seconds worldwide (1). Hospitalization is a high-risk period for patients to commit suicide (2); specifically, the suicide rate of inpatients in general hospitals is 8.25 times higher than that in the general population $(3,4)$. Suicide rates among hospital inpatients also increase with age; specifically, during the same period, the suicide mortality rate of people 
aged 65 years and above is significantly higher than that of the general population during the same period. Therefore, elderly inpatients should be closely monitored for suicidal behavior. Suicide risk assessment is the primary measure for preventing suicide. A simple and appropriate suicide risk assessment tool can assist medical staff to identify high-risk individuals in time, so as to initiate early intervention and consequently reduce the inpatient suicide rates.

In clinical practice, a 5 -item brief symptom rating scale (BSRS-5), also known as a "mood thermometer", is a commonly used tool for evaluating inpatient suicide risk. Based on its ease of operation and condensed items, it can be used to quickly gather patients' psychological status information with good reliability and validity. In this study, we aimed to evaluate the suicide risk of elderly inpatients utilizing the BSRS-5. On the basis of the assessment, the influencing factors of suicide risk were further explored, thus providing scientific evidence for the construction of a suicide prevention system for elderly inpatients.

We present the following article in accordance with the STROBE reporting checklist (available at https://dx.doi. org/10.21037/apm-21-1443).

\section{Methods}

\section{Participants}

A total of 1,841 elderly hospitalized patients of the Renji Hospital South Campus, Shanghai Jiaotong University of Medicine from April 2020 to August 2020 were selected by convenience sampling. The inclusion criteria were as follows: age $\geq 60$ years; male or female; clear consciousness and no cognitive impairment; cooperation in completing the BSRS-5 scale. The exclusion criteria were as follows: severe hearing impairment; illiteracy; severe illness resulting in inability to complete the scale. All procedures performed in this study involving human participants were in accordance with the Declaration of Helsinki (as revised in 2013). The study was approved by the Ethics Committee of Renji Hospital, School of Medicine, Shanghai Jiaotong University, and informed consent was taken from all the patients.

\section{Design}

\section{Study tools}

\section{General information questionnaire}

We designed the questionnaire according to the study objective, including general participants information such as gender, age, length of stay, disease diagnosis, and the specific conditions such as self-care ability and pain intensity.

\section{BSRS-5}

The BSRS-5 was first introduced by Lung (5) and developed by Professor Mingbin Li from the Department of Psychiatry, College of Medicine, National Taiwan University School. This scale contains 5 items selected from the BSRS-50 that are highly correlated with each other, and includes an additional question. Specifically, BSRS-5 measures the following symptoms: difficultly falling asleep, experiencing annoyance or anger, feeling down or depressed, sense of inferiority to others, and having suicidal thoughts.

The total score of BSRS-5 is 24 points, with $0-4$ points for each item (0: not present, 1: slight, 2: moderate, 3 : severe, 4: extremely severe). The results of the total score are interpreted as follows: $<3$ : no suicidal ideation (sensitivity 0.83 , specificity 0.86 ), $\geq 6$ : a cut-off point for psychiatric cases, and $>13$ : presence of suicidal ideation. In addition to human immunodeficiency virus (HIV) inpatients and psychiatric inpatients, the scale was also distributed to outpatients, rehabilitation patients, college freshmen, and community members. Its internal consistency (Cronbach's $\alpha$ ) was found to be $0.77-0.90$ and retest reliability was 0.82 .

\section{Barthel index (BI)}

The BI, designed by Barthel and Mahoney (6), is a scale that is commonly utilized in assessing activities of daily living (ADL) in American rehabilitation institutions. Due to its simple operation, high reliability, and validity, BI has been widely introduced to ADL assessment. This scale includes 10 items, including feeding, bathing, grooming, dressing, bowel control, bladder control, toilet use, bed to chair and back, mobility on level surfaces, and stairs. The total score of this scale is 100 points, and the interpretation of the score is as follows: 100: independence, 61-99: mild dependence, $41-60$ : moderate dependence, and $\leq 40$ : severe dependence.

\section{Numeric rating scale (NRS)}

The NRS first proposed by Melzack (7) is a commonly used tool for rating pain. At present, it is the easiest method among those used in clinical practice to diagnose postoperative pain of medical institution patients, as well as for subjective pain assessment. The NRS is easily understood and accepted by patients, and its results are reliable. Patients can verbally describe their pain intensity from 0 to 10 points (0: no pain, 1-3: mild pain, 4-6: moderate pain, 7-10: severe pain), with 10 points representing the highest intensity of pain. 
Table 1 General information of all elderly inpatients

\begin{tabular}{|c|c|c|}
\hline Item & Frequency & Constituent ratio (\%) \\
\hline \multicolumn{3}{|l|}{ Gender } \\
\hline Male & 1,014 & 55.10 \\
\hline Female & 827 & 44.90 \\
\hline \multicolumn{3}{|l|}{ Age (years) } \\
\hline $60-65$ & 599 & 32.50 \\
\hline $66-70$ & 493 & 26.80 \\
\hline $71-75$ & 343 & 18.60 \\
\hline 76 and above & 406 & 22.10 \\
\hline \multicolumn{3}{|l|}{$\mathrm{BI}$} \\
\hline Independence & 602 & 32.70 \\
\hline Mile dependence & 809 & 43.90 \\
\hline Moderate dependence & 278 & 15.10 \\
\hline Severe dependence & 152 & 8.30 \\
\hline \multicolumn{3}{|l|}{ NRS } \\
\hline No pain & 1,371 & 74.50 \\
\hline Mild pain & 404 & 21.90 \\
\hline Moderate pain & 51 & 2.80 \\
\hline Severe pain & 15 & 0.80 \\
\hline \multicolumn{3}{|l|}{ BSRS-5 } \\
\hline Patients without suicide risk & 1,825 & 99.10 \\
\hline Patients at risk of suicide & 16 & 0.90 \\
\hline
\end{tabular}

$\mathrm{BI}$, Barthel index; NRS, numeric rating scale; BSRS-5, 5-item brief symptom rating scale.

\section{Statistical analysis}

On completion of data entry by two researchers, the software SPSS 23.0 (IBM Corp., Armonk, NY, USA) was used to establish a database and for subsequent statistical analysis. The chi-square test and $t$-test were adopted for univariate analysis. Then, logistic regression was performed using the variables with $\mathrm{P}<0.05$ as independent variables, and suicide risk as the dependent variable. A statistically significant difference was indicated if $\mathrm{P}<0.05$.

\section{Results}

\section{General information}

The general information of 1,841 included elderly inpatients
Table 2 General information of inpatients at risk of suicide

\begin{tabular}{|c|c|c|}
\hline Item & Frequency & Constituent ratio (\%) \\
\hline \multicolumn{3}{|l|}{ Gender } \\
\hline Male & 10 & 62.50 \\
\hline Female & 6 & 37.50 \\
\hline \multicolumn{3}{|l|}{ Age (years) } \\
\hline $60-65$ & 5 & 31.25 \\
\hline $66-70$ & 3 & 18.75 \\
\hline $71-75$ & 3 & 18.75 \\
\hline 76 and above & 5 & 31.25 \\
\hline \multicolumn{3}{|l|}{$\mathrm{BI}$} \\
\hline Independence & 5 & 31.25 \\
\hline Mild dependence & 2 & 12.50 \\
\hline Moderate dependence & 3 & 18.75 \\
\hline Severe dependence & 6 & 37.50 \\
\hline \multicolumn{3}{|l|}{ NRS } \\
\hline No pain & 9 & 56.25 \\
\hline Mild pain & 6 & 37.50 \\
\hline Moderate pain & 1 & 6.25 \\
\hline Severe pain & 0 & 0 \\
\hline
\end{tabular}

$\mathrm{BI}$, Barthel index; NRS, numeric rating scale.

is shown in Table 1, while that of inpatients at risk of suicide is shown in Table 2.

\section{Univariate analysis of suicide risk in elderly inpatients}

Univariate analysis was performed with the BSRS-5 score as the dependent variable and patient gender, age, self-care ability, and pain intensity as independent variables. The results showed that self-care ability $(\mathrm{F}=3.195, \mathrm{P}=0.000)$ and pain intensity $(\mathrm{F}=3.247, \mathrm{P}=0.001)$ were statistically significant (Table 3).

\section{Logistic regression analysis of suicide risk in elderly inpatients}

To investigate the relationship of suicide risk with selfcare ability and pain intensity, the scores of the 3 scales were assigned as follows: BSRS- 5 : lowest $-3=0$, 4-highest $=1$; BI: lowest $-40=0,41-60=1,60-99=2,100=3$, NRS: $0=0$, $1-3=1,4-6=2,7-10=3$. The results showed that self-care 
Table 3 Univariate analysis of suicide risk in elderly inpatients

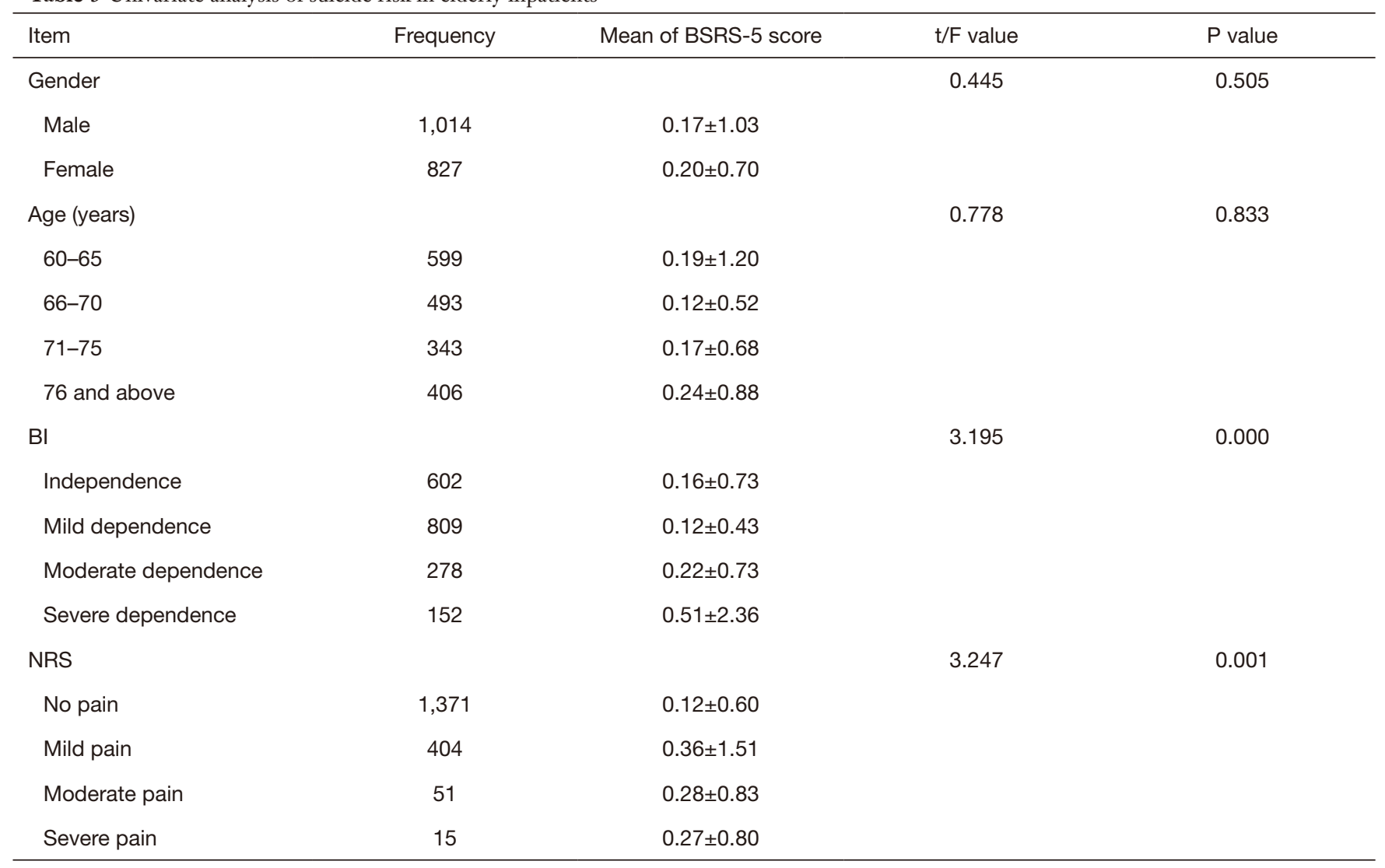

$\mathrm{BI}$, Barthel index; NRS, numeric rating scale.

Table 4 Logistic regression analysis of suicide risk in elderly inpatients

\begin{tabular}{|c|c|c|c|c|c|c|c|c|}
\hline Step $1^{a}$ & B & Standard error & Wald & $\begin{array}{l}\text { Degrees of } \\
\text { freedom }\end{array}$ & Significance & $\operatorname{Exp}(B)$ & \multicolumn{2}{|c|}{$\operatorname{EXP}(B) 95 \% \mathrm{Cl}$ for EXP (B) } \\
\hline $\mathrm{Bl}$ assignment & -0.657 & 0.253 & 6.750 & 1 & 0.009 & 0.519 & 0.316 & 0.851 \\
\hline NRS assignment & 0.383 & 0.359 & 1.138 & 1 & 0.286 & 1.467 & 0.726 & 2.965 \\
\hline Constant & -3.767 & 0.478 & 62.070 & 1 & 0.000 & 0.023 & - & - \\
\hline
\end{tabular}

a, variables entered in step 1: BI assignment, NRS assignment. Cl, confidence interval; BI, Barthel index; NRS, numeric rating scale.

ability assignment was statistically significant $(\mathrm{P}=0.009<0.05$, $\mathrm{B}=-0.657)$, suggesting that self-care ability score affected the risk of suicide in elderly inpatients (Table 4). Specifically, the weaker their self-care ability, the higher the suicide risk.

\section{Discussion}

\section{Influencing factors of suicide risk in elderly inpatients}

Many factors affect suicide risk among inpatients, including disease, psychological, family, economic, and environmental factors. In this study, we found that self-care ability of elderly inpatients is an independent factor for their suicide risk; the worse their self-care ability, the higher the suicide risk. Our finding is consistent with that of Zhang et al. (8). Studies have shown that restriction in ADL is a crucial influencing factor of suicidal ideation, especially for the elderly who experience decreased self-care ability with age (9). The decline in selfcare ability leads to physical weakness, and reduced or even 
loss of work ability of the elderly. Therefore, the elderly are unable to independently resolve their strong sense of hopelessness and self-blame, view thinking themselves as a burden to their families, and consequently experience suicidal ideations (10). Hence, for elderly inpatients with poor self-care ability, it is necessary to build and fortify their social support system and actively explore appropriate rapid rehabilitation strategies, so as to reduce their suicide risk.

\section{A 3-level system for suicide prevention in elderly inpatients}

Medical advances contribute to a growing proportion of disabled and semi-disabled elderly inpatients; concurrently, suicide risk also increases in the elderly due to the loss of self-care ability. Therefore, establishing a system of risk identification is a critical measure to prevent suicide among elderly inpatients. First, a simple and sensitive suicide screening tool suitable for medical staff was selected; second, according to the screening results, a 3-level system for suicide prevention was carried out for patient at low, moderate, and high risks. The suicide risk, in this study, was graded according to the BSRS-5 score. Specifically, people with a total score $\geq 6$ on items $1-5$ were deemed to be at low suicide risk, and were recommended to talk to families or friends; people with a total score $\geq 10$ were deemed to be at moderate suicide risk, and were recommended to seek psychological counseling; people with a total score $\geq 15$ or a score $\geq 1$ on item 6 were deemed to be at high suicide risk, were classified as requiring high care and more ward rounds, and were also recommended to seek professional psychotherapy or psychiatric treatment.

\section{Conclusions}

Suicidality in elderly inpatients is mainly related to selfcare ability. Effective strategies to reduce their suicide risk include establishment of a social support system, improvement of nursing ability of their family members, and promotion of rehabilitation, diagnosis, and treatment strategies. Additionally, it is necessary to establish a 3-level system for suicide prevention based on the application of an effective and feasible screening tool. The BSRS-5 tool used in this study is worthy of in-depth exploration to fully elucidate its clinical value.

\section{Acknowledgments}

Funding: This work was supported by the Shanghai Hospital
Association (X2020083) and the School of Medicine, Shanghai Jiaotong University (ZT201902).

\section{Footnote}

Reporting Checklist: The authors have completed the STROBE reporting checklist. Available at https://dx.doi. org/10.21037/apm-21-1443

Data Sharing Statement: Available at https://dx.doi. org/10.21037/apm-21-1443

Conflicts of Interest: All authors have completed the ICMJE uniform disclosure form (available at https://dx.doi. org/10.21037/apm-21-1443). The authors have no conflicts of interest to declare.

Ethical Statement: The authors are accountable for all aspects of the work in ensuring that questions related to the accuracy or integrity of any part of the work are appropriately investigated and resolved. All procedures performed in this study involving human participants were in accordance with the Declaration of Helsinki (as revised in 2013). The study was approved by the Ethics Committee of Renji Hospital, School of Medicine, Shanghai Jiaotong University, and informed consent was taken from all the patients.

Open Access Statement: This is an Open Access article distributed in accordance with the Creative Commons Attribution-NonCommercial-NoDerivs 4.0 International License (CC BY-NC-ND 4.0), which permits the noncommercial replication and distribution of the article with the strict proviso that no changes or edits are made and the original work is properly cited (including links to both the formal publication through the relevant DOI and the license). See: https://creativecommons.org/licenses/by-nc-nd/4.0/.

\section{References}

1. Turecki G, Brent DA. Suicide and suicidal behaviour. Lancet 2016;387:1227-39.

2. Zalsman G, Hawton K, Wasserman D, et al. Evidencebased national suicide prevention taskforce in Europe: A consensus position paper. Eur Neuropsychopharmacol 2017;27:418-21.

3. Riblet N, Shiner B, Mills P, et al. Systematic and organizational issues implicated in post-hospitalization 
suicides of medically hospitalized patients: A study of root-cause analysis reports. Gen Hosp Psychiatry 2017;46:68-73.

4. Tseng MC, Cheng IC, Hu FC. Standardized mortality ratio of inpatient suicide in a general hospital. J Formos Med Assoc 2011;110:267-9.

5. Lung FW, Lee MB. The five-item Brief-Symptom Rating Scale as a suicide ideation screening instrument for psychiatric inpatients and community residents. BMC Psychiatry 2008;8:53.

6. Mahoney FI, Barthel DW. Functional Evaluation: The Barthel Index. Md State Med J 1965;14:61-5.

7. Melzack R. The McGill Pain Questionnaire: major properties and scoring methods. Pain 1975;1:277-99.

8. Zhang L, Sun L, Zhou C, et al. The Relationship Between

Cite this article as: Zhu D, Zhu Z, Gu J, Luan W. Application of a 5-item brief symptom rating scale to evaluate suicide risk in elderly inpatients. Ann Palliat Med 2021;10(7):7613-7618. doi: 10.21037/apm-21-1443
Difficulties in Daily Living and Suicidal Ideation Among Older Adults: Results From a Population-Based Survey in Shandong. J Nerv Ment Dis 2018;206:211-6.

9. Dennis M, Baillon S, Brugha T, et al. The influence of limitation in activity of daily living and physical health on suicidal ideation: results from a population survey of Great Britain. Soc Psychiatry Psychiatr Epidemiol 2009;44:608-13.

10. Zhang $W$, Ding $H$, Su $P$, et al. Does disability predict attempted suicide in the elderly? A community-based study of elderly residents in Shanghai, China. Aging Ment Health 2016;20:81-7.

(English Language Editor: J. Jones) 